\title{
EFFECT OF MICROENCAPSULATION ON SURVIVAL AND STABILITY OF BIFIDOBACTERIUM BIFIDUM BBO1 EXPOSED TO SIMULATED GASTROINTESTINAL CONDITIONS AND IN DIFFERENT FOOD MATRICES
}

\author{
- Research paper - \\ He CHEN*1, Donglin MA*, Yichao Li**, Yu LIU**, Ye WANG* \\ *School of Food and Biological Engineering, Shaanxi University of Science and Technology, \\ Xi'an, 710021, China \\ **Shaanxi Heshi Dairy Co. Ltd., Baoji, 721200, China
}

\begin{abstract}
Bifidobacterium bifidum BB01 was microencapsulated by extrusion method with sodium alginate. This paper aimed to study the survival rate of microencapsulating Bifidobacterium bifidum BB01 in simulated gastrointestinal conditions, resistance to artificial bile salt and stability during storage. Results showed non-microencapsulated Bifidobacterium bifidum BB01 were more susceptible than microencapsulated under simulated gastrointestinal conditions, and microencapsulated Bifidobacterium bifidum BB01 exhibited a lower population reduction than free cells during exposure to simulated gastrointestinal, The enteric test showed that the microorganism cells were released from the monolayer microcapsules, double microcapsules and trilayer completely in 40min. The viable counts of monolayer microcapsules, double layer microcapsules and triple layer microcapsules decreased by nine magnitudes, four magnitude and one magnitude after $2 \mathrm{~h}$, respectively. Moreover, in fruit orange, pure milk and nutrition Express, the optimum storage times of free Bifidobacterium bifidum BB01, monolayer microcapsules, double layer microcapsules and triple layer microcapsules were 21 days, 21 days, 28 days and more than 35 days at $4^{\circ} \mathrm{C}$, but at room temperature the optimum storage time were 7 days, 14 days, 21 days and more than 28 days, and the viable counts were maintained at $1 \times 10^{6} \mathrm{CFU} \mathrm{g}^{-1}$ or more.
\end{abstract}

Keywords: Bifidobacterium bifidum BB01, Stability, Simulated gastrointestinal

\section{INTRODUCTION}

Probiotics are a group of live microorganisms which can stabilize the bowel microflora and promote the health of the host (Goldin et al., 1998). Lactobacillus and Bifidobacteria have been shown to play a beneficial role in immune regulation and reduction and prevention of various intestinal diseases (Shah et al. 2007). However, Bifidobacteria are sensitive to heat, moisture, oxygen and acid condition, it will exhibit some challenge to apply in the dairy industry. Probiotics must be living in the process of their reach host and play a beneficial role in the host (Ying et al.,
2016). The study showed that the minimal activity of maintaining the probiotic function of bacteria concentration should be higher than $10^{7} \mathrm{CFU} \mathrm{mL} \mathrm{mL}^{-1}$ (Homayouni et al., 2008). Probiotics have to resist bad environment to play its beneficial role in the gastrointestinal tract (Doleyres et al., 2004). So, it need a method to decrease injure for Bifidobacteria in the gastrointestinal tract. The resistence of bifidobacteria in the gastric juice is generally low (Collado and Sanz et al. 2006). Moreover, the count of viable bacteria in the process of food processing and storage is also important (Anal and Singh, 2007). The benefits of probiotics have been extensively studied in a

${ }^{1}$ Corresponding author. Mailing address: chenhe419@gmail.com Acta Universitatis Cibiniensis Series E: FOOD TECHNOLOGY Vol. XXI (2017), no. 1 
variety of foods (Kailasapathy et al., 2008; Souza and Saad et al. 2009).

Microencapsulate probiotics can provide a physical barrier to against harsh environmental conditions consist of $\mathrm{pH}$, hydrogen peroxide, and oxygen (Park et al., 2016). There are a lot of materials used for microencapsulation, such as alginate, gum arabic, gelatine, maltodextrin, pectin, skim milk, starch, and chitosan (Li et al., 2011). Microencapsulation by spray drying has been successfully used in the food industry for several decades (Gouin, 2004). Compared with spray drying, freeze drying and fluidized bed drying, a major highlight of microencapsulation with hydrocolloids is that cells are entrapped within the matrix during the formation of the spheres (Krasaekoopt et al., 2003). Doleyres et al. (2005) demonstrated to

\section{MATERIALS AND METHODS}

Microorganism: The strains of $B$. bifidum BB01, obtained from School of Food and Biological Engineering, Shaanxi University of Science \& Technology, were cultured for $24 \mathrm{~h}$ in the MRS-broth at $37{ }^{\circ} \mathrm{C}$, the cell suspension was harvested by centrifugation at $4000 \mathrm{rpm}$ for $10 \mathrm{~min}$ at $4{ }^{\circ} \mathrm{C}$, and washed twice with physiological saline. The viable count was adjusted to $1.0 \times 10^{11} \mathrm{CFU} \mathrm{\textrm {mL } ^ { - 1 }}$ finally.

Microencapsulation: B. bifidum BB01 was encapsulated in $2 \%$ sodium alginate solutions that sterilized by autoclaving for 15 min at $121^{\circ} \mathrm{C}$ and cooled to $38-40^{\circ} \mathrm{C}$. The mixture including $5 \mathrm{~mL} 2 \%$ sodium alginate solutions and $1 \mathrm{~mL}$ of free cell suspension (FS) were transferred into a centrifuge tube and the content was vortexed to homogeneity, and oil-water-oil ratios 6:1, $0.8 \%$ Tween 80 and the alginate-cell mixture were added into a beaker while stirring magnetically. After $15 \mathrm{~min}$, a uniformly emulsion was obtained where $2 \%$ calcium chloride with a syringe quickly to harden microcapsules. The capsules were harvested by centrifuging at $4000 \mathrm{rpm}$ for 10 min. The $1 \%$ chitosan solution was added protect probiotics by microencapsulation in hydrocolloid capsules prepared by extrusion or emulsion. Nevertheless, the survival of probiotics exposure to acid environment was less satisfactory, Albertini et al. (2010) reported the survival of the cells dramatically decreased within a few weeks of storage in gastric juice.

In our previous works, the significant factors and process for microencapsulation of $B$. bifidum BB01 were studied by Box-Behnken design (Chen, et al, 2014; Chen, et al, 2016). The objective of this study was to evaluate the survival rate and stability of Ca-alginate microencapsulated Bifidobacterium bifidum BB01 (B. bifidum BB01) expose to simulated gastrointestinal conditions and in different food matrices.

and mixed with above mentioned monlayer microcapsules for $30 \mathrm{~min}$, and then the chitosan coated sodium alginate double layer microcapsuled (DM) were formed and washed with sterile saline solution for three times. The palm oil was added and mixed with above mentioned double layer microcapsules for $30 \mathrm{~min}$. Finally, the palm oil coated sodium alginate-chitosan beads were formed and washed with sterile saline solution for three times. Thus, the free $B$. bifidum BB01, alginate sodium encapsulated $B$. bifidum BB01 cells (MM), alginate-chitosan encapsulate $B$. bifidum BB01 (DM), and alginate-chitosan-palm oil encapsulate $B$. bifidum BB01 (TM) were obtained for further evaluation of survival and storage stability.

Viable count: $B$. bifidum BB01 was measured by pour plate technique on MRS agar. The samples $(1 \mathrm{~g})$ to be tested were dissolved in sterile saline solution, and then it was diluted at 10 times, $1 \mathrm{~mL}$ bacterial suspension of the dilution degree of $10^{-7}$ or $10^{-8}$ was inoculated on MRS agar in triplicate. After incubation at $37{ }^{\circ} \mathrm{C}$ for 48 $\mathrm{h}$, the total viable count was performed and it is expressed by colony-forming unit per $\mathrm{mL}$ 
or g. The viable counts of microcapsules were determined according to Eq. (1):

$$
\mathrm{VC}=\mathrm{N} \times \mathrm{T} \times 10 \ldots(1)
$$

where $\mathrm{VC}$ is viable counts of $B$. bifidum $\mathrm{BB} 01$ suspension on per a milliliter. $\mathrm{N}$ is the average viable count in triplicate. $\mathrm{T}$ is dilution degree.

Survival of B. bifidum BB01 under simulated gastrointestinal conditions

Gastric juice tolerance test: The solution to simulate gastric juice conditions was HP ( $0.16 \%$ hydrogen chloride, $0.1 \%$ pepsin). Microcapsules of $B$. bifidum BB01 were washed in saline solution, and the viable cells of microcapsules were released in the solution containing 3\% trisodium citric acid. $1 \mathrm{~mL}$ bacterial suspension from free cells and the microencapsulated cells were added into tubes including $9 \mathrm{~mL}$ of HP adjusted to $\mathrm{pH} 1.2$, The anaerobic tubes were cultured at $37^{\circ} \mathrm{C}$ for $0 \mathrm{~h}, 1 \mathrm{~h}$ and $2 \mathrm{~h}$, the survival rate of the free and the encapsulated B. bifidum BB01 was measured by pour plating technique on MRS agar.

Bile salt tolerance test: free cell suspension and microencapsulated cells were added to 9 $\mathrm{mL}$ of artificial simulated bile salt solution containing $1 \%$ bile salts, respectively. The samples were treated at $37{ }^{\circ} \mathrm{C}$ for $0 \mathrm{~h}, 1 \mathrm{~h}$ and $2 \mathrm{~h}$ (Truelstrup Hansen et al., 2002; Chandramouli et al., 2004) and viable counts of the free and microencapsulated were

\section{RESULTS AND DISCUSSIONS}

\section{Survival of B. bifidum BB01 in simulated gastrointestinal conditions}

Acid tolerance test: As Table 1 shows, the number of viable bacteria of B. bifidum BB01 under acid conditions for non-microen-capsulated and microencapsulated had been reduced as the extension of treatment time. However, compared with double layer micro capsules and triple layer micro capsules, there was a notable decline in the number of living bacteria of free B. bifidum BB01 under simulated acid measured by agar MRS.

Enteric experiments in simulated intestinal tract: To evaluate the release time of microencapsulating cells under simulated intestinal fluid, microcapsules (1g) are added test tubes including $9 \mathrm{~mL}$ prewarmed $\left(37^{\circ} \mathrm{C}\right)$ simulated intestinal fluid $(1.38 \%$ potassium dihydrogen phosphate, $0.4 \%$ sodium hydroxide, and $1 \%$ pancreatic enzymes), and the viable counts are measured by pour plating in tubes after incubation at $37^{\circ} \mathrm{C}$ for $0 \mathrm{~h}, 1 \mathrm{~h}$ and $2 \mathrm{~h}$.

The stability test microcapsules of $B$. bifidum BB01 in food: Taking $1 \mathrm{~g}$ of microcapsules of $B$. bifidum BB01 into the 9 $\mathrm{mL}$ of fruit orange, nutrition Express and pure milk, respectively, and then the number of viable cells, $\mathrm{pH}$, and acidity will be measured every 7 days at $4^{\circ} \mathrm{C}$ and room temperature, respectively. Meanwhile, the control group experiments will be performed by adding $B$. bifidum BB01 suspension into fruit orange, nutrition Express and pure milk.

Determination of $\boldsymbol{p H}$ : During the period of fruit orange, nutrition Express and pure milk storage, acidity meter (PHs-3c) will be directly used to determine the $\mathrm{pH}$ at room temperature and $4^{\circ} \mathrm{C}$ (Hu et al. 2010).

Determination of acidity: The acidity $\left({ }^{\circ} \mathrm{T}\right)$ was determined by titration (Denkova et al., 2013).

conditions, and the experimental results of acid resistance in $2 \mathrm{~h}$ showed that the viable counts of free B. bifidum BB01 soon decreased to 0 . The viable counts of monolayer microcapsules, double layer microcapsules and triple layer microcapsules decreased by nine magnitudes, four magnitudes and one magnitude, respectively. Because there is no protection or weak protection for free $B$. bifidum $\mathrm{BB} 01$ and monolayer microcapsules so that cannot resist the acid environment, but for double layer microcapsules and triple layer microcapsules, because of the protection of microcapsules, $B$. bifidum BB01 acid resistance were enhanced. These results were similar to those obtained by 
Lian, Hsiao and Chou et al (2004), and Annan, Borza and Truelstrup et al (2008), which illustrated double layer and three layers Bifidobacterium microcapsules have a better stability and a stronger resistance to acid.

Table 1. Resistance to acid of microencapsulated B. bifidum BB01

\begin{tabular}{|c|c|c|c|}
\hline Sample & 0 & $1 \mathrm{~h}$ & $2 \mathrm{~h}$ \\
\hline FS & $3.41 \times 10^{9}$ & $1.09 \times 10^{3}$ & 0 \\
\hline MM & $2.67 \times 10^{9}$ & $6.23 \times 10^{4}$ & 0 \\
\hline DM & $2.16 \times 10^{9}$ & $2.12 \times 10^{6}$ & $4.99 \times 10^{5}$ \\
\hline TM & $2.16 \times 10^{9}$ & $0.92 \times 10^{9}$ & $3.56 \times 10^{8}$ \\
\hline
\end{tabular}

FS: free suspension, MM: monolayer microcapsules, DM: double layer microencapsules, TM: triple layer microcapsules

On the other hand, Yang et al., (2012) adopted the methods of air suspension microencapsulation to produce microencapsulation of immune colostrum and Bifidobacterium, which didn't disintegrate in simulated gastric juice for $2 \mathrm{~h}$, and the survival rate of viable cell count was $67.7 \%$ in simulated gastric juice treated with $2 \mathrm{~h}$. Castro-Cislaghi et al (2012) concluded that reason for the decrease in viable count of Bifidobacterium bb12 microencapsulated with whey was due to the different strains of microorganisms. what's more; Sun et al. (2000) detected that number of viable cells of free Bifidobacterium infantis ATCC 15697 decreased from $1.233 \times 10^{9} \mathrm{CFU} \mathrm{mL}^{-1}$ to an undetectable level in simulated gastric juices $(\mathrm{pH} 2.5)$ after $30 \mathrm{~min}$; however, the viable counts microencapsulated with gellan-xanthan decreased by only $0.67 \mathrm{log}$ cycle at the same time, which showed that the microencapsulation would protect Bifidobacterium infantis ATCC 15697 from the harsh acid environment in the stomach. Annan et al. (2008) detected the viable count microencapsulated with alginate gelatin were 7.6 $\log \mathrm{CFU} \mathrm{mL} \mathrm{mL}^{-1}$ after incubation in simulated gastric $(\mathrm{pH} 2.0,2 \mathrm{~h})$, resulting in significantly $(P<0.05)$ higher viable numbers than were obtained for free cells due to the buffering effect of intact microspheres. In addition, A decrease in free cells after $3 \mathrm{~h}$ was more $2 \mathrm{log}$ compared to microencapsulated
Bifidobacterium BB-12 in vitro acid conditions (Fritzen-Freireet al. 2013).

Bile salt tolerance test: Table 2 showed the survival rate of free and microencapsulated $B$. bifidum BB01 in bile salt solution for different treated times. A decrease was detected in the viability for free $B$. bifidum $\mathrm{BB} 01$, and monolayer microcapsules in comparison to double layer microcapsules and triple layer microcapsules. The experimental result of cholateproof showed that the viable counts of free $B$. bifidum BB01 and monolayer microcapsules soon decreased to 0 after 2 hours, but the viable counts of double layer microcapsules and triple layer microcapsules were $6.89 \times 10^{5} \mathrm{CFU} \mathrm{mL}^{-1}, 5.92 \times 10^{8} \mathrm{CFU} \mathrm{mL}^{-1}$, respectively.

Table 2 shows the viable counts of monolayer microcapsules, double layer microcapsules and triple layer microcapsules decreased by nine magnitudes, four magnitudes and one magnitude after $2 \mathrm{~h}$, respectively.

Table 2. Bile tolerance of microencapsulated $B$. bifidum BB01

\begin{tabular}{|c|c|c|l|}
\hline Sample & 0 & $1 \mathrm{~h}$ & \multicolumn{1}{c|}{$2 \mathrm{~h}$} \\
\hline FS & $3.41 \times 10^{9}$ & $0.91 \times 10^{4}$ & 0 \\
\hline MM & $2.67 \times 10^{9}$ & $2.01 \times 10^{5}$ & 0 \\
\hline DM & $2.16 \times 10^{9}$ & $1.92 \times 10^{7}$ & $5.99 \times 10^{5}$ \\
\hline TM & $2.16 \times 10^{9}$ & $0.98 \times 10^{9}$ & $4.31 \times 10^{8}$ \\
\hline
\end{tabular}

FS: free suspension, MM: monolayer microcapsules, DM: double layer microencapsules, TM: triple layer microcapsules

Because there was no protection or weak protection for free B. bifidum BB01 and monolayer microcapsules so that cannot resist the acid environment, but for double layer microcapsules and triple layer microcapsules, because of the protection of microcapsules, $B$. bifidum BB01 acid resistance were enhanced. Similar findings were obtained by $\mathrm{Li}$ et al. (2011), which illustrated microencapsulation $B$. bifidum BB01 have a better stability and stronger resistance to acid.

Yang et al., (2012) adopted the methods of air suspension microencapsulation to produce microencapsulation, after 3 hours of treatment in high salt solution the survival rate of viable 
cell could still reach $67.7 \%$. According to Carlise et al. (2012), the viable count of free and microencapsulated Bifidobacterium BB-12 with reconstituted skim milk and inulin, and reconstituted skim milk and oligofructoseenriched inulin decreased 2.39 and $2.32 \mathrm{log}$ CFU g ${ }^{-1}$ after $6 \mathrm{~h}$ of incubation respectively. Mandal et al. (2006) found that the survival rate of microencapsulated $L$. casei NCDC 298 with alginate lied in the bile concentration and wall material was high, and the resulted encapsulated probiotics can be exploited in development of probiotic functional foods with better survival of sensitive probiotic organisms. In addition, Sohail et al. (2011) noted the viable count of probiotics is highly relate to the being microencapsulated species in alginate gel microbeads using a novel impinging aerosols method. Fabiane Picinin De Castro-Cislaghi et al. (2012) noted microencapsulation with whey cannot protect probiotic, but for this present study with sodium alginate, chitosan and palm oil to protect probiotic cells, which results showed that the survival rate of the B. bifidum BB01 microcapsules in bile was satisfactory.

In vitro gastrointestinal enteric test: Three different microcapsules were esitimated by the time of releasing entrapped bacteria from microcapsules in simulated intestinal solution (Table 3). The viable cells released from monolayer microcapsules more than double layer microcapsules and triple layer microcapsules after $20 \mathrm{~min}$, and the number of viable cells reached the maximum when the microcapsules were treated for $40 \mathrm{~min}$. More than $40 \mathrm{~min}$, the number of living bacteria showed a downward trend after continuously being treated. The enteric test showed that the microorganism cells were released from the monolayer microcapsules, double microcapsules and trilayer completely in $40 \mathrm{~min}$. these results were similar to those obtained by Yang et al., (2012). So, the method of using microcapsules to protect probiotics was effective. Truelstrup Hansen, L., et al. (2002) noted the factors that determine enteric acid time of microcapsules was leaching of $\mathrm{Ca}^{2+}$ from the alginate gel that can obviously $(\mathrm{P}<0.05)$ decreased the released viable
count.Matias et al. (2016) found that decreased $4.2 \log$ under simulated gastrointestinal conditions after $6 \mathrm{~h}$ by the PMA-qPCR method. Annan et al. (2007) evaluated the number of surviving cells coated alginate were $7.4 \mathrm{log}$ CFU $\mathrm{mL}^{-1}$ in simulated intestinal juices $(4 \mathrm{~h})$. Moreover, Martoni et al. (2007) demonstrated the viable count of $L$. plantarum $80 \mathrm{BSH}+$ was maintained above $10^{10} \mathrm{CFU} \mathrm{mL} \mathrm{m}^{-1}$ after $3 \mathrm{~h}$, $6 \mathrm{~h}$, and $12 \mathrm{~h}$ residence times in bile concentrations up to $1.0 \%$. What's more, the decrease in the viable population by $3.45 \mathrm{log}$ units for free Bifidobacteria lactis $\mathrm{Bb}-12$ cells was similar to findings by Truelstrup Hansen et al. (2002) who observed reductions of about $3 \log$ CFU mL $\mathrm{mL}^{-1}$ for Bifidobacteria lactis Bb-12 exposed to SGJ (pH 2.0) for 2 to $3 \mathrm{~h}$.

Table 3. The results from the enteric test of $B$. bifidum BB01 microcapsules

\begin{tabular}{|c|c|c|c|}
\hline Sample & $\begin{array}{l}20 \\
(\min )\end{array}$ & $\begin{array}{l}40 \\
(\min )\end{array}$ & $60(\min )$ \\
\hline MM & $1.60 \times 10^{7}$ & $2.67 \times 10^{9}$ & $2.16 \times 10^{9}$ \\
\hline $\mathrm{DM}$ & $0.83 \times 10^{6}$ & $2.16 \times 10^{9}$ & $2.00 \times 10^{9}$ \\
\hline TM & $1.62 \times 10^{6}$ & $2.16 \times 10^{9}$ & $2.01 \times 10^{9}$ \\
\hline
\end{tabular}

Zhang, F., et al (2011) used alginate as wall materials to encapsulated Bifidobacterium bifidum, and the embedding rate reached $72.32 \%$. Theses microcapsules were disaggregation subtotal after $15 \mathrm{~min}$ in simulated intestinal juices, and the release rate was $96 \%$. Due to the special nature of Bifidobacteria bifidum, single wall material of micro encapsulation was typically less than ideal protection. Mi et al (2013) combined carboxymethyl chitosan with alginate, two kinds of wall materials, to encapsulate Bifidobacterium longum BIOMA 5920; encapsulation yield and enteric solubility were superior to that microcapsules encapsulated by single wall material. Our present study used microencapsulation to protect probiotics resist adverse environment, and experiments also demonstrated the microorganism cells were released from the monolayer microcapsules, double microcapsules and trilayer completely in 40min, so the method was effective. 
The stability test for the microcapsules of $B$. bifidum BB01 in food: Mixing monolayer microcapsules, double layer layers microcapsules and triple layer microcapsules with fruit orange, nutrition Express and pure milk by $1 / 9(\mathrm{~m} / \mathrm{v})$ and the free $B$. bifidum BB01 suspension were used as the control groups. After storing for a period of time at $4^{\circ} \mathrm{C}$ and room temperature, the number of live bacteria, acidity and $\mathrm{pH}$ were measured at intervals 7 days, respectively. Experimental results were shown in Figures 1 to 6 . All figures in below FS、MM、DM and TM were the free $B$. bifidum BB01 suspension, monolayer microcapsules, double layer microcapsules and triple layer microcapsules, respectively.

Figures 1 and 2 show the stability of free $B$.

bifidum BB01, monolayer microcapsules, double layer microcapsules and triple layer microcapsules in fruit orange and nutrition Express. It can be seen from the figures that the rate of decrease of viable counts of free $B$. bifidum BB01, monolayer microcapsules, double layer microcapsules and triple layer microcapsules decreased in sequence under $4{ }^{\circ} \mathrm{C}$ and room temperature. The optimum storage time of free B. bifidum BB01, monolayer microcapsules, double layer microcapsules and triple layer microcapsules was 21 days, 21 days, 28 days and more than 35 days at $4^{\circ} \mathrm{C}$, and the optimum storage time was 7 days, 14 days, 21 days and 28 days at room temperature, respectively. The main reason for the decrease in the number of viable bacteria was that the environment in fruit orange and nutrition Express was acidic, which could inhibit or even kill some of the bacteria. The viable counts were maintained at $1 \times 10^{6} \mathrm{CFU} \mathrm{g}^{-1}$ or more.

Figure 3 showed the viable counts of free Bifidobacterium BB01, monolayer microcapsules, double layer microcapsules and triple layer microcapsules all remained unchanged nearly in pure milk at $4^{\circ} \mathrm{C}$, the reason for this phenomenon were that the temperature inhibited the growth and reproduction of the bacteria, what's more, the $\mathrm{pH}$ value of pure milk was close to neutral, which was suitable for the preservation of $B$. bifidum $\mathrm{BB} 01$. With the extension of storage time, the acidity increased and the corresponding $\mathrm{pH}$ value decreased in fruit orange, nutrition Express and pure milk, the decreased trend was very significant for acidity in pure milk, especially. The experimental results demonstrated that the application of $B$. bifidum $\mathrm{BB} 01$ was more suitable for pure milk, and the viable counts were maintained at $1 \times 10^{6} \mathrm{CFU} \mathrm{g}^{-1}$ or more in 35 days.

Lactobacillus acidophilus LA5 and Bifidobacterium lactis Bb-12 in alginate solely and either combined with cashew flower or green tea extracts could improve the stability of the probiotic upon storage at $4^{\circ} \mathrm{C}$ for 30 days (Chaikham et al 2015). Akalin and Erisir (2008) detected an obvious decrease regarding to the viable count of Bifidobacterium $\mathrm{Bb}-12$ microencapsulated in low-fat ice creams including oligofructose or inulin, but Matias, Padilha., et al (2016) found the viable count of Bifidobacterium $\mathrm{Bb}-12$ were slightly exceeding $6 \log \mathrm{CFU} \mathrm{g^{-1 }}$ in ice cream with oligofructose storaged for 90 days, meanwhile, it also showed that the viability of B.animalis $\mathrm{Bb}-12$ in all synbiotic apple ice cream storaged for 84days was around 7.5 to $8.5 \log$ CFU g ${ }^{-1}$, which results was satisfactory. Tripathi et al., (2014) reported that the reason of the survival of probiotics faced with adverse factors in processing and preservation was strain dependent. What's more, the stability of microencapsulation of Bifidobacterium in food also had a certain relation with the wall material, Chen, C., et al (2014) prepared using sodium alginate and chitosan both wall materials to produce Bifidobacterium BB01 and BB28 microcapsules, and results indicated that these two kinds of polymers were used to prepare Bifidobacterium microcapsules had good acid resistance, enteric and storage stability. 

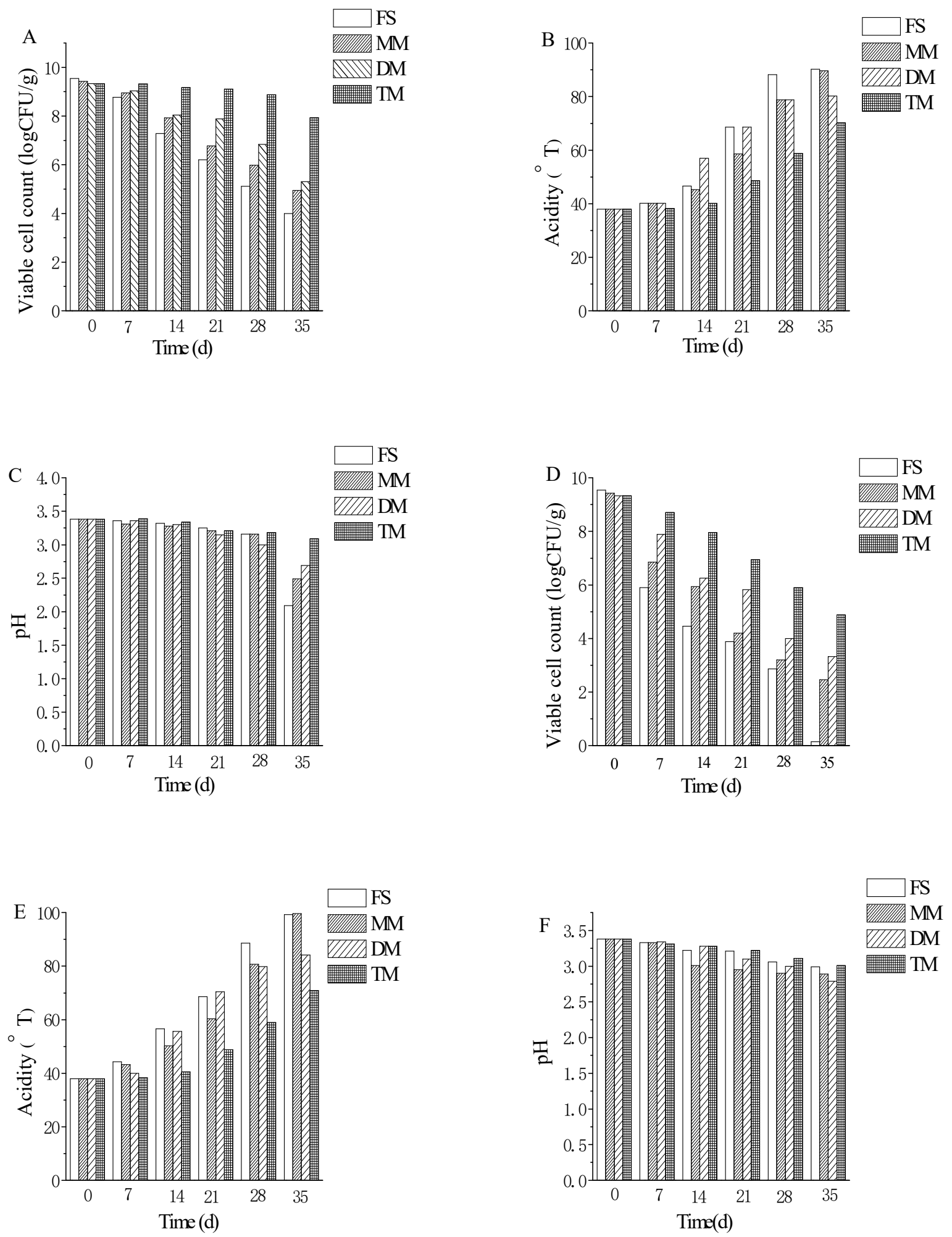

Figure 1. The viable cell count, acidity and $\mathrm{pH}$ of B. bifidum $\mathrm{BB} 01$ in fruit orange at $4{ }^{\circ} \mathrm{C}$ and room temperature $\left(4^{\circ} \mathrm{C}\right.$ : A. B. C; room temperature: D. E. F; FS, free cell suspension; MM, monolayer microencapsule; DM, double layer microcapsules; TM, three layer microcapsules). 

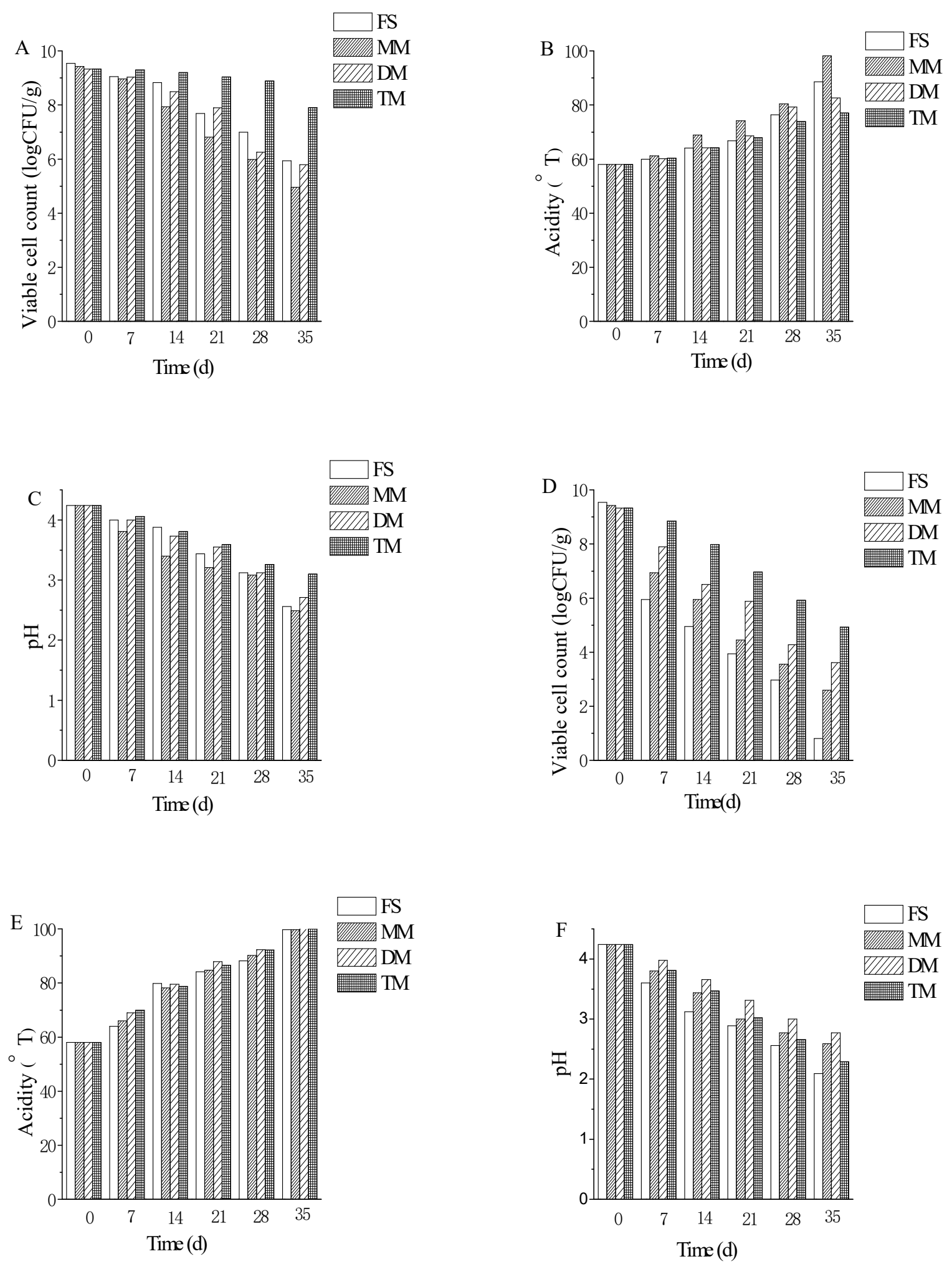

Figure 2. The viable cell count, acidity and $\mathrm{pH}$ of B. bifidum $\mathrm{BB} 01$ in nutrition Express at $4^{\circ} \mathrm{C}$ and room temperature $\left(4^{\circ} \mathrm{C}\right.$ : A. B. C; room temperature:D. E. F, FS, free cell suspension; MM, monolayer microencapsule; DM, double layer microcapsules; TM, three layer microcapsules) 

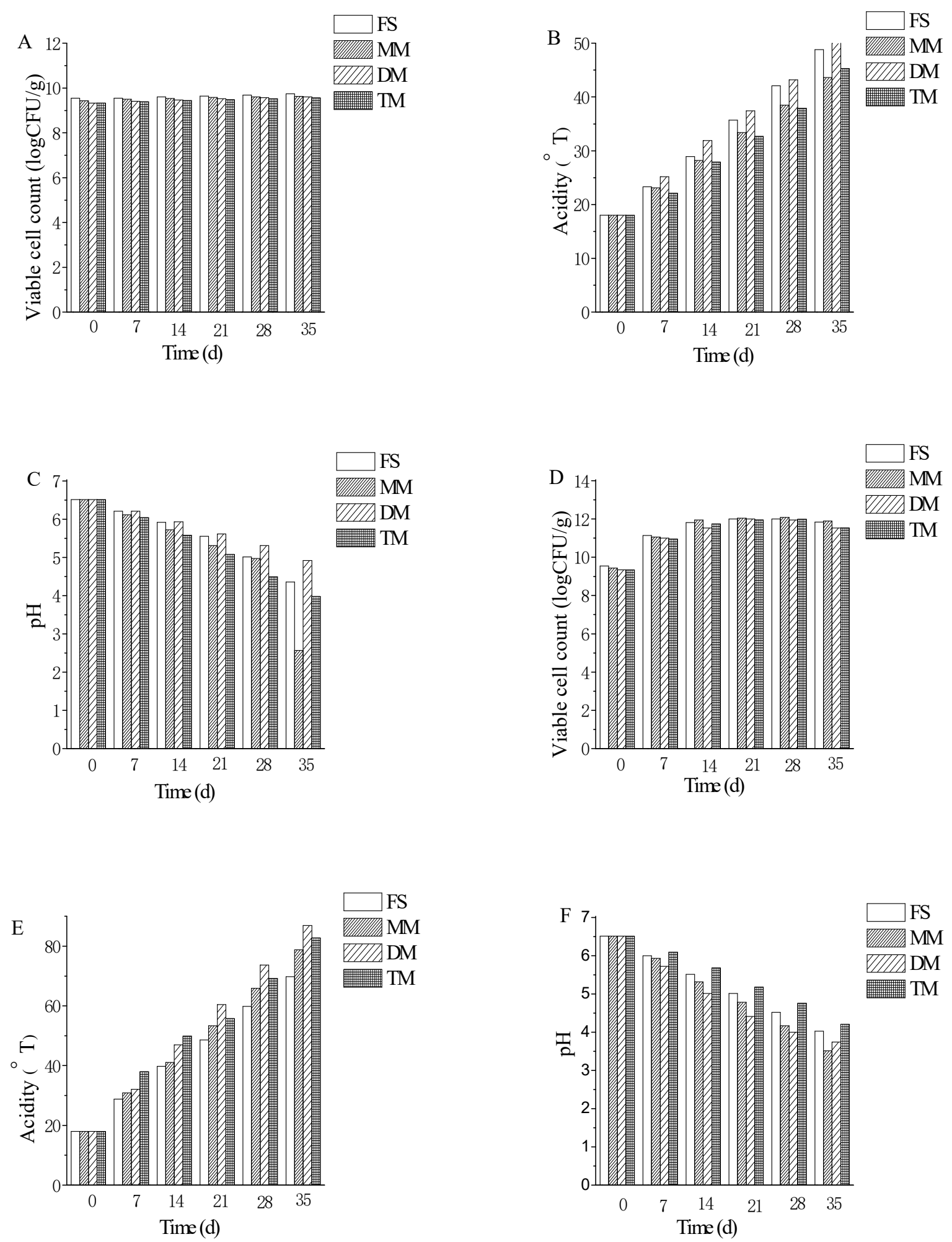

Figure 3. The viable cell count, acidity and $\mathrm{pH}$ of B. bifidum $\mathrm{BB} 01$ in pure milk at $4{ }^{\circ} \mathrm{C}$ and room temperature. $\left(4^{\circ} \mathrm{C}\right.$ : A. B. C; room temperature:D. E. F, FS, free cell suspension; MM, monolayer microencapsule; DM, double layer microcapsules; TM, three layer microcapsules)

On the other hand, Sun, W., et al. (2000) found the survival of immobilized and free cells in yogurt no obvious losses Storaged for 4 weeks, and the viable counts were maintained at $1 \times 10^{6}$
CFU $\mathrm{g}^{-1}$ or more, but a significant difference $(\mathrm{P}<0.05)$ was observed at 5 weeks, 6 weeks and 7 weeks for immobilized and free cells. Aragon-Alegro et al. (2007) demonstrated that 
viable count of Lactobacillus paracasei subsp remained above $7 \log \mathrm{CFU} \mathrm{g}^{-1}$ during storage for 28 days in probiotic chocolate mousse. However, Borges et al. (2004) noted a decrease by $3 \log$ in the viable count of Lactobacillus

\section{CONCLUSIONS}

This study demonstrated that encapsulated $B$. bifidum BB01 were superior to non-encapsulated in the resistance to gastric acid, bile resistant and stability in the food. Experimental results in a simulated gastrointestinal showed that the viable counts of free B. bifidum BB01 decreased to 0 after $2 \mathrm{~h}$, and the viable counts of monolayer microcapsules, double layer microcapsules and triple layer microcapsules decreased by nine magnitudes, four magnitudes and one magnitude, respectively. The enteric test showed that the microorganism cells were released from the monolayer microcapsules, double paracasei subsp during storage 20 days in mousses added with free cells, and the viable count of probiotic microencapsulated with alginate decreased $2 \log$.

microcapsules and trilayer completely in 40min. which demonstrated the application of the microcapsules of B. bifidum BB01 in food. In addition, in fruit orange, pure milk and nutrition Express, the optimum storage time of free B. bifidum BB01, monolayer microcapsules, double layer microcapsules and triple layer microcapsules were 21 days, 21 days, 28 days and more than 35 days at $4^{\circ} \mathrm{C}$, but the optimum storage time were 7 days, 14 days, 21 days and more than 28 days at room temperature, and the viable counts were maintained at $1 \times 10^{6} \mathrm{CFU} \mathrm{g}^{-1}$ or more. The experimental results showed that the double layer layer and the three layers of microcapsules of $B$. bifidum BB01 have great application potential in food.

\section{ACKNOWLEGEMENTS}

The authors wish to gratefully acknowledge the Shaanxi Province Science and Technology Innovation Project co-ordination Program, China (No. 2016KTCL02-30).

\section{REFERENCES}

1. Akalin, A.S.\& Erisir, D. (2008). Effects of inulin and oligofructose on the rheological characteristics and probiotic culture survival in low-fat probiotic ice cream. Food Sci. 73, M184-188. DOI: 10.1111/j.1750-3841.2008.00728.

2. Albertini, B. Vitali, B. Passerini, N. Cruciani, F. Di Sabatino, M. Rodriguez, L. \& Brigidi, P. (2010). Development of microparticulate systems for intestinal delivery of Lactobacillus acidophilus and Bifidobacterium lactis. European Journal of Pharmaceutical Sciences, 40, 359-366. DOI: 10.1016/j.ejps.2010.04.011.

3. Anal, A.K. \& Singh, H. (2007). Recent advances in microencapsulation of probiotics for industrial applications and targeted delivery. Trends in Food Science and Technology, 18, 240-251. DOI: 10.1016/j.tifs.2007.01.004.

4. Annan, N.T. Borza, A.D. \& Truelstrup, L.H. (2008). Encapsulation in alginate-coated gelatin microspheres improves survival of the probiotic Bifidobacterium adolescentis $15703 \mathrm{~T}$ during exposure to simulated gastro-intestinal conditions. Food Research Internationa, 41(2),184-193. DOI: $10.1016 /$ j.foodres.2007.11.001.

5. Aragon-Alegro, L. C. Alegro, J. H. A. Cardarelli, H. R. Ming, C. C. \& Saad, S. M. I. (2007). Potentially probiotic and synbiotic chocolate mousse. LWT - Food Science and Technology, 40(4), 669-675. DOI: 10.1016/j.lwt.2006.02.020.

6. Borges, J.Q. Ferreira, S.R.S.S. \& Costa, G.W. (2004). Cinética de sobrevivência de Lactobacillus acidophilus microencapsulados em matriz de alginato de cálcio eveiculados em musse de chocolate. In: Congresso Brasileiro de Ciência e Tecnologia de Alimentos, 19, Recife, 2004. 
7. Castro-Cislaghi, F. P. D. Silva, C. D. R. E. Fritzen-Freire, C. B. Lorenz, J. G. \& Sant'Anna, E. S. (2012). Bifidobacterium, bb-12 microencapsulated by spray drying with whey: survival under simulated gastrointestinal conditions, tolerance to nacl, and viability during storage. Journal of Food Engineering, 113(2), 186-193. DOI: 10.1016/j.jfoodeng.2012.06.006.

8. Chaikham, P. (2015). Stability of probiotics encapsulated with thai herbal extracts in fruit juices and yoghurt during refrigerated storage. Food Bioscience, 12, 61-66. DOI: 10.1016/j.fbio.2015.07.006.

9. Chandramouli, V. Kailasapathy, K. Peiris, P. \& Jones, M. (2004). An improved method of microencapsulation and its evaluation to protect Lactobacillus spp. In simulated gastric conditions. Journal of Microbiological Methods, 56, 27-35. DOI: 10.1016/j.mimet.2003.09.002.

10. Chen, C. Yang, J. Zhu, J, P. \& Sun, Y, X. (2012). Research progress of wall materials and methods of probiotic microcapsule. Science and technology of food industry, 33(14), 403-407. DOI: 1002-0306(2012)14-0403-05

11. Chen, H., Ma, D.L., Li Y.C., Liu Y. \& Wang. (2016). Optimization the process of microencapsulation of Bifidobacterium bifidum BB01 by Box-Behnken design. Acta Universitatis Cibiniensis Series E: FOOD TECHNOLOGY, 20(2):17-28. DOI: 10.1515/ aucft-2016-0012

12. Chen, H., Song, Y, J., Wang, Y., \& Shu, G, W. (2014). Effect of Cell Suspension-Alginate Ratio, Tween 80 and Oil-Water Ratio on microcapsulation of B. bifidum BB01 and BB28. Journal of Pure and Apply Microbiology, 8(2), 1167-1172.

13. Cínthiahb, S. \& Susanami, S. (2009). Viability of lactobacillus acidophilus la-5 added solely or in co-culture with a yoghurt starter culture and implications on physico-chemical and related properties of minas fresh cheese during storage. Food Science \& Technology, 42(2), 633-640.

14. Collado, C.M. \& Sanz, Y. (2006). Method for direct selection of potentially probiotic Bifidobacterium strains from human feces based on their acid-adaptation ability. Journal of Microbiological Methods, 66, 560-563. DOI: 10.1016/j.mimet.2006.01.007.

15. Denkova, R. Ilieva, S. Nikolova, D. Evstatieva, Y. Denkova, Z. \& Yordanova, M., et al. (2013). Antimicrobial activity of lactobacillus plantarum $\mathrm{x} 2$ against pathogenic microorganisms. Bulgarian Journal of Agricultural Science, 19(2), 108-111.

16. Doleyres, Y. \& Lacroix, C. (2005). Technologies with free and immobilised cells forprobiotic bifidobacteria production and protection. International Dairy Journal, 15, 973-988. DOI: 10.1016/j.idairyj.2004.11.014.

17. Doleyres, Y. Fliss, I. \& Lacroix, C. (2004). Increased stress tolerance of Bifidobacterium longum and Lactococcus lactis produced during continuous mixed-strain immobilized-cell fermentation. Journal of Applied Microbiology, 97, 527-539. DOI: 10.1111/j.1365-2672.2004. 02326.x

18. Fritzenfreire, C. B. Prudêncio, E. S. Pinto, S. S. Muñoz, I. B. \& Rdmc, A. (2013). Effect of microencapsulation on survival of bifidobacterium bb-12 exposed to simulated gastrointestinal conditions and heat treatments. LWT - Food Science and Technology, 50(1), 39-44. DOI: 10.1016/j.lwt.2012.07.037.

19. Goldin, B. R. (1998). Health benefits of probiotics. British Journal of Nutrition, 80(80), S203-7. DOI: $10.1111 /$ j.1748-0159. 2009. 00147.x

20. Gouin, S. (2004). Micro-encapsulation: Industrial appraisal of existing technologies and trends. Trends in Food Science and Technology, 15, 330-347. DOI: 10.1016/j.tifs. 2003.10.005.

21. Homayouni, A. Azizi, A. Ehsani, M. R. Yarmand, M. S. \& Razavi, S. H. (2008). Effect of microencapsulation and resistant starch on the probiotic survival and sensory properties of synbiotic ice cream. Food Chemistry, 111(1), 50-55. DOI: 10.1016/j.food chem.2008.03.036.

22. Hu, M. Chen, H. \& Shu, G, W. (2010). Study on Bifidobacterium bifidum culture and lyoprotectant [D]. Shaanxi University of Science and Technology, 21-22.

23. Kailasapathy, K. Harmstorf, I. \& Phillips, M. (2008). Survival of L. acidophilus and B. animalis ssp. Lactis in stirred fruit yogurts. LWT-Food Science and Technology, 41 (7), 1317-1322. DOI: 10.1016/j.lwt.2007.08.009. 
24. Krasaekoopt, W. Bhandari, B. \& Deeth, H. (2003). Review: evaluation of encapsulation techniques of probiotics for yoghurt. International Dairy Journal, 13 (1), 3-13. DOI:10.1016/S0958-6946(02)00155-3.

25. Li, X.Y. Chenb, X.G. Suna, Z.H. Parkc, H.J. \& Chac, D.S. (2011). Preparation of alginate/Chitosan/carboxymethyl chitosan complex microcapsules and application in Lactobacillus casei ATCC 393. Carbohydrate Polymers, 83, 1479-1485. DOI: 10.1016/j.carbpol.2010.09.053.

26. Mandal, S. Puniya, A.K. \& Singh, K. (2006). Effect of alginate concentrations on survival of microencapsulated Lactobacillus casei NCDC-298. International Dairy Journal, 16, 1190-1195. DOI: 10.1016/j.idairyj.2005.10.005.

27. Martoni, C., Bhathena, J., Jones, M.L., Urbanska, A.M., Chen, H., \& Prakash, S. (2007). Investigation of microencapsulated BSH active Lactobacillus in the simulated human GI tract. Journal of Biomedicine and Biotechnology, 2007, 13684-13684. DOI: 10.1155/2007/13684.

28. Matias, N. S. Padilha, M. Bedani, R. \& Saad, S. M. I. (2016). In vitro, gastrointestinal resistance of lactobacillus acidophilus, la-5 and bifidobacterium animalis, bb-12 in soy and/or milk-based synbiotic apple ice creams. International Journal of Food Microbiology, 234, 83-93. DOI: 10.1016/j.ijfoodmicro.2016.06.037.

29. Mi, Y. Su, R. Fan, D. D. Zhu, X. L. \& Zhang, W. N. (2013). Preparation of no- carboxymethyl chitosan coated alginate microcapsules and their application to bifidobacterium longum, bioma 5920. Materials Science \& Engineering C Materials for Biological Applications, 33(5), 3047-53. DOI: $10.1016 /$ j.msec.2013.03.035.

30. Park, H. J. Lee, G. H. Jun, J. H. Son, M. Choi, Y. S. \& Choi, M. K., et al. (2016). Formulation and in vivo evaluation of probiotics-encapsulated pellets with hydroxypropyl methylcellulose acetate succinate (hpmcas). Carbohydrate Polymers, 136, 692-699. DOI: 10.1016/j.carbpol.2015.09.083.

31. Shah, N. P. (2007). Functional cultures and health benefits. International Dairy Journal, 17(11), 1262-1277. DOI: 10.1016/j.idairyj.2007.01.014.

32. Sohail, A. Turner, M. Coombes, A., Bostrom, T. \& Bhandari, B. (2011). Survivability of probiotics encapsulated in alginate gel microbeads using a novel impinging aerosols method. International Journal of Food Microbiology, 145, 162-168. DOI: 10.1016/j.ijfoodmicro.2010.12.007.

33. Sun, W. \& Griffiths, M. W. (2000). Survival of bifidobacteria in yogurt and simulated gastric juice following immobilization in gellan-xanthan beads. International Journal of Food Microbiology, 61, 17-25. DOI: 10.1016/S0168-1605(00)00327-5.

34. Tripathi, M.K. \& Giri, S.K. (2014). Probiotic functional foods: Survival of probiotics during processing and storage. J. Funct. Foods, 9, 225-241. DOI: 10.1016/j.jff.2014.04.030.

35. Truelstrup Hansen, L. Allan-Wojtas, P.M. Jin, Y.L. \& Paulson, A.T. (2002). Survival of Ca-alginate microencapsulated Bifidobacterium spp. in milk and simulated gastrointestinal conditions. Food Microbiology, 19, 35-45. DOI: 10.1006/fmic.2001.0452.

36. Yang, L. You, L. X. Zhang, Y. L. Chen, H. Y. Yang, B. \& Zhang, F. K. (2012). Processing Characteristics of Compound Microcapsules of Immune Colostrum and Bifidobacteria. Food science, 23, 150-154. DOI: 1002-6630(2012)23-0150-05

37. Ying, D. Y. Sanguansri, L. \& Weerakkody, R. et al. (2016). Effect of encapsulant matrix on stability of microencapsulated probiotics. Journal of Functional Foods, 25,447-458. DOI: 10.1016/j.jff.2016.06.020.

38. Zhang, F. Zhao, M. Wang, W. \& Hu, T. F. (2011). Encapsulation of bifidobacterium bifidum in improved alginate microcapsules to prolonging viability. Advanced Materials Research, 183-185, 1481-1485. DOI: 10.4028/www.scientific.net/AMR.183-185.1481. 